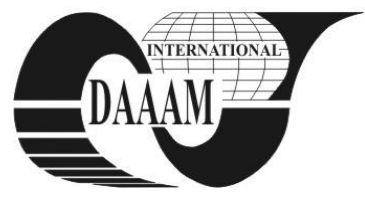

\title{
VOCATIONAL TRAINING FOR MANAGERS IN COMPANIES FROM ROMANIAN WESTERN REGION
}

\author{
LUT, D[ina] M[aria]
}

\begin{abstract}
The paper presents results of a study aiming to identify the real needs of vocational training for managers in companies from Western Region of Romania, in order to design their training programs, in partnership between business and academia.
\end{abstract}

Key words: training managers, Romanian companies, business environment, management systems, decision process

\section{INTRODUCTION}

Business environment in our country, as well as worldwide, is currently both very aggressive in terms of competitiveness and totally unpredictable. Therefore, in such an environment, managers encounter many difficulties when they implement successful strategies or when they adopt methods and techniques to enhance efficacy. However, the development of viable strategies is an issue of great concern that can ensure, even in an environment as turbulent as that of the Romanian economy, the survival and effectiveness of organizations. Moreover, in a turbulent economic and financial environment, with unpredictable developments, there are great risks yet also development opportunities difficult to imagine in a stable economy. In this context, we believe that the time has come for Romanian managers to initiate supported actions aiming at implementing management methods and techniques that can provide organizations with a considerable increase of economic efficiency, regardless of the existence of disturbing factors that come from outside.

Based on these considerations, this study aims to identify the real needs of training for managers in the Romanian Western Region companies, in order to improve their management performance and increase the efficiency of firms from which they come.

\section{OBJECTIVES AND RESEARCH METHODOLOGY}

The study was conducted on a group of managers (middle managers and top managers) belonging to active companies (from medium and large companies category) in the Western Region of Romania (from all the counties of this region - Timis, Arad, Caras-Severin, Hunedoara), working in different economic areas: industrial-production $(57 \%)$, trade $(16 \%)$, services $(27 \%)$. I used the survey as a research method, and the questionnaire as a research tool. The questionnaire was designed to contribute to the following specific objectives of the study:

1. To identify the tools used for planning activities;

2. To analyze the methods used in the management of decision process;

3. To identify means of coordination, evaluation and control of activities;

4. To identify the modern management systems implemented in the investigated companies, in order to increase business efficiency and competitiveness;

5. To analyze training programs for managers in investigated companies;
The questionnaire was distributed by e-mail to the companies that agreed to participate in the study, that were also members of Chambers of Commerce, Industry and Agriculture of the four counties. Finally, 91 validated questionnaires filled in by top and middle managers participated in this research.

\section{RESEARCH RESULTS}

After processing the information provided by the surveys and after the interpretation of the results, the following conclusions were drawn, appropriate to the objectives set:

\subsection{Planning activities}

Within the investigated companies, the main tools used in planning activities are budgets (in $81 \%$ of the companies investigated), production and sales plans $(71 \%)$, investment plans (52\%), and marketing plans (44\%). As sources for gathering information to develop strategies and plans, most companies investigated $(79 \%)$ used as primary sources of information (especially information gathered by the firm) and secondary (information collected by third parties and made public). Regarding the timeframe for designing the planning, the overwhelming majority of firms $(91 \%)$ practiced mostly short and medium term planning (up to 3 years) and less long term planning. This is an indicator of both the uncertainty regarding the future of business and its instability, and possibly a managerial incapacity of long-term forecasting.

\subsection{Management of decision process}

$71 \%$ of respondents believe that the most difficult and complex decisions are decisions taken under conditions of uncertainty and that their share in all decisions has increased in the last three years. These responses highlight once again the continuing instability and unpredictable business environment in Romania in the last recent years. Regarding the methods and tools used in the management of decision process, only $47 \%$ of managers said they use scientific methods of decision making (Decision-Tree method, Cause-Effect diagrams, and Multicriteria lists) (Powell \& Baker, 2010). This shows that most of the interviewed managers still use empirical methods in the process of decision, although these methods are inadequate in the context of current business environment and in the situations encountered in business management complexity.

\subsection{Coordination, evaluation and control of activities}

Managerial control tools used in the companies investigated are diverse, indicating thus that the management function of control and evaluation is well represented in the companies investigated, being implemented by various scientific tools, such as: cost analysis (78\% of firms), performance appraisal of employees $(71 \%)$, quality inspection of products / services $(61 \%)$, analysis of activity reports $(61 \%)$. In order to estimate and evaluate the effectiveness of business, the companies use several types of performance indicators. All managers interviewed said that in the companies they come from, economic and financial indicators are the main category of 
performance indicators used. A possible explanation for this is related to the current economic legislation in Romania, which requires all firms to report such indicators quarterly, half yearly or annually.

\subsection{Implementation of modern management systems}

Regarding the management systems implemented in the investigated companies, in order to increase business efficiency and competitiveness, we have recorded the following results: the quality management system was implemented in $72 \%$ of the companies investigated, environmental management system $37 \%$ of firms, and health and safety at work management system- $26 \%$ of firms. Regarding the new management systems, as Kaizen Management (Masaaki, 1997) and Lean Management (Mann, 2005), the results show that these systems are less known by the managers interviewed and are not implemented in the investigated companies.

\subsection{Training programs for managers in the companies surveyed}

Analyzing the responses of managers surveyed on the number of management training courses, attended by the time the survey, results are worrying. A considerable proportion $(21.56 \%)$ of managers said they did not participate in any training in management, until the questioning. On willingness to participate in other future trainings, managers surveyed are divided into two groups: those who believe that a leading position requires training and constant training throughout their careers - they said they would like to attend the short courses in their work area or in management area $(80.4 \%$ of managers surveyed); and those who believe that training is concluded with the requirements for a position of leadership - they do not necessarily want to pursue such programs in the near future (19.6\% of managers surveyed). When asked what would be the top three areas of interest they would train in, in the near future, the managers surveyed provided the following areas: management (87\%), economics/finance $(43 \%)$, and communication - PR (41\%). In the course of management topics, respondents indicated an interest in topics such as Lean management system (72\%), Kaizen management system (67\%) and quality management system (33\%). Based on responses to questions about the importance of different skills / abilities that a middle or top manager of a company must have (Peterson \& Van Fleet, 2004), we can conclude that in the opinion of managers surveyed most important skills are: communication skills (76\%), cognitive skills (43\%), and technical skills (36\%).

\section{DISCUSSIONS AND CONCLUSIONS}

Following analysis and interpretation of study results, we conclude that in the investigated companies, there is a particular concern for developing and practicing scientific management. This is largely due to managerial experience and successful results achieved by the multinational companies present in our country and which includes some of the companies investigated. There is also an interest in planning, organizing and coordinating of activities with scientific methods and tools, as evidenced by the existence and use of various types of plans and various means of control and by the implementation of management systems to streamline business firms. However, the concepts or methods that emphasize long-term vision of managers and their ability to react and respond to business constraints (for example: social responsibility issues, the use of modern management systems, the use of scientific methods to substantiate decisions under uncertainty, etc.) are less known and less represented in the companies investigated.

The profession of a manager is a very complex profession, requiring a person to be effective in many activities. There is an old controversy between experts expressed by the question: "Managers are born or can be created through education and training?" We believe (like many other experts, in fact), that while talent and natural inclinations undoubtedly have an important role, becoming a manager is the result of a professional and personal transformation process. Therefore, training programs and professional development of managers play a key role, especially considering that the managers act in the context of an aggressive and unpredictable business environment as the present one. The study's results show that these programs leave much to be desired in terms of rigor and systematic way of organizing them. Romanian managers should be aware that in the current business environment, being a manager is a major responsibility that requires a conscious and continuous process of learning and personal transformation. Therefore, under such conditions, investment in training and professional development of both managers and all employees is an absolute necessity, an investment with long-term effects, and not just an expense, as we show in other studies (Lut \& Mitariu, 2010). Therefore, we believe that vocational training programs for managers should be intensified, and the mix of training methods should be improved to match the real development needs of managers throughout their work and in order to increase the economic efficiency of organizations they come from.

\section{FURTHER RESEARCH}

The results of this study were forwarded to businesses environment in the Western Region of Romania and also to academia, in order to provide a starting point in a partnership between the two parties. This partnership wants to support improvement training of managers, by organizing programs and courses in this regard.

This research was conducted on a relatively small number of companies and has no national expansion. However, we believe that it can be very useful in identifying real training needs for managers. Such research may be the basis for other research undertaken at national level and can also be the basis for designing national training programs for managers who come from both private and public companies.

\section{ACKNOWLEDGEMENTS}

This paper is the result of a research in the frame of the R\&D project with the theme: "Study on the analysis of effectiveness and impact of Mind Lab educational program usage, for managerial skills development, in order to promote the program on the management training market." The project is running under contract between "Dimitrie Cantemir" Christian University and a private economic operator.

\section{REFERENCES}

Lut, D.; Mitariu, C. (2010). Considerations Regarding the Human Resource Management in the Romanian Trade Enterprises in Annals of DAAAM for 2011 \& Proceedings of the 21st International DAAAM Symposium, ISSN 17269679, ISBN 978-3-901509-83-4, Editor B[ranko] Katalinic, Published by DAAAM International, Vienna, Austria 2010, pp. 1427-1429

Mann, D. (2005). Creating a Lean Culture: Tools to Sustain Lean Conversions, Productivity Press, ISBN 978-1-56327322-3, New York

Masaaki, I. (1997). Gemba Kaizen: A Commonsense, Low-cost Approach to Management, McGraw-Hill, ISBN 0-07031446-2, USA

Peterson, T.O.; Van Fleet, D. (2004). "The ongoing legacy of R.L. Katz: An updated typology of management skills", Management Decision, Vol. 42, Issue 10, pp.1297-1308, ISSN 0025-1747, USA

Powell, S.; Baker K. (2010). Management Science: The Art of Modeling with Spreadsheets, John Wiley \& Sons, Inc., NJ, ISBN 978-0-470-53067-2 